\title{
POLA POPULASI KUMBANG LUCANID (COLEOPTERA:LUCANIDAE) PADA BERBAGAI TIPE HABITAT DI HUTAN GUNUNG SALAK, JAWA BARAT
}

\author{
Roni Koneri ${ }^{1)}$ \\ ${ }^{1)}$ Program Studi Biologi, FMIPA, Universitas Sam Ratulangi \\ Jalan Kampus Unsrat, Manado 95115 \\ e-mail: ronicaniago@yahoo.com
}

\begin{abstract}
ABSTRAK
Penelitian ini bertujuan untuk mengkaji pola populasi kumbang lucanid di hutan Gunung Salak. Data populasi kumbang lucanid diperoleh dengan menggunakan perangkap lampu (light trap). Penelitian dilaksanakan di kawasan hutan Gunung Salak dan berlangsung dari bulan Mei 2004 sampai Desember 2005. Hasil penelitian menunjukkan bahwa kelimpahan populasi di alam mencapai puncaknya pada bulan April dan Mei. Spesies yang selalu muncul setiap bulan selama pengamatan adalah Cyclomatus canaliculatus, Prosopocoilus astocoides dan Hexarthrius buqueti.
\end{abstract}

Kata kunci: Gunung Salak, kumbang lucanid, populasi.

\section{POPULATION PATTERN OF LUCANID BEETLE IN DIFFERENT HABITAT TYPE AT SALAK MOUNTAIN, WEST JAVA}

\begin{abstract}
ABSRACT
The objectives of the research were to study temporal dynamic pattern of Lucanid beetle in different habitat type. Research was conducted between May 2004 and December 2005. Beetles were surveyed by using light traps in three different forest types. Results have indicated that temporal dynamic pattern of Lucanid beetle was affected by forest disturbance level. Highest number of Lucanid beetles were recorded in April dan May. Species which always emerge each month during perception is Cyclomatus canaliculatus, Prosopocoilus astocoides and Hexarthrius buqueti.
\end{abstract}

Keywords: Salak mountain, lucanids beetle, population.

\section{PENDAHULUAN}

Populasi kumbang di alam dipengaruhi oleh dinamika lingkungannya. Dinamika yang terjadi berupa perubahan fenologi tumbuhan hutan, kondisi fisik, iklim dari waktu ke waktu mempengaruhi reproduksi, pertumbuhan dan mortalitasnya. Perubahan ini secara langsung atau tidak akan menyebabkan perubahan jumlah serangga tersebut (Kahono \& Amir, 2003).

Pola populasi kumbang lucanid di hutan Gunung Salak sangat penting dipelajari, karena dari informasi ini akan dapat diperoleh waktu keluarnya imago untuk kawin dan mencari makan. Selain itu informasi ini juga berguna untuk melihat waktu yang sangat berbahaya untuk perburuan dan perdagangan imago kumbang lucanid. Beberapa penelitian tentang fluktuasi serangga telah dilaporkan, seperti: pengaruh perangkap cahaya terhadap fluktuasi kumbang permukaan tanah (ground beetle) selama sepuluh tahun (Yahiro \& Yano, 1997), hubungan antara iklim dengan fluktuasi kupu-kupu (Woong, 2003), hubungan antara teknik pengambilan sampel dengan fluktuasi kelimpahan kumbang (flying Coleoptera) (Hosking, 1979) dan fluktuasi curah hujan dengan komunitas serangga di Taman Nasional Gunung Halimun (Kahono \& Noerdjito, 2001).

Bagaimana pola populasi kumbang lucanid di hutan Gunung Salak karena kerusakan habitat dan iklim belum pernah dilakukan. Padahal penelitian ini dapat memberikan informasi ilmiah tentang pola populasi kumbang lucanid di hutan Gunung Salak sebagai data untuk konservasi 
serangga tersebut. Penelitian ini bertujuan untuk mengkaji pola populasi kumbang lucanid di kawasan hutan Gunung Salak.

\section{BAHAN DAN METODE}

\section{Waktu dan Tempat Penelitian}

Penelitian dimulai bulan Mei 2004 samapai Desember 2005. Penelitian dilakukan di kawasan hutan Gunung Salak Jawa Barat yang secara administratif termasuk wilayah Kabupaten Sukabumi dan Kabupaten Bogor.

\section{Pelaksanaan penelitian}

Pola populasi kumbang lucanid yang dimaksud disini adalah kehadiran kumbang lucanid atau jumlah kumbang lucanid yang terkoleksi setiap bulan selama setahun yang berasal dari perangkap lampu yang dilakukan pada tiga tingkat gangguan hutan (hutan tidak terganggu, hutan kurang terganggu dan hutan sangat terganggu).

\section{Cara koleksi kumbang lucanid}

Pengambilan data struktur komunitas kumbang lucanid dilakukan menggunakan perangkap lampu (light trap). Perangkap lampu terdiri dari lampu bohlam mercury 160 watt, bohlam 20 watt dan halogen 300 watt 220 volt, ketiga bohlam dipasang di depan layar kain putih $(2 \times 2 \mathrm{~m})$ selama 5 jam (pukul 18-23 wib) pada setiap titik pengambilan sampel pada bulan gelap. Perangkap lampu dipasang dengan ketinggian \pm 2 meter di atas permukaan tanah. Total titik pengambilan sampel sebanyak 18 titik, dengan masing masingmasing 6 titik sampel pada setiap tingkat kerusakan hutan.

Jarak antar titik pada setiap lokasi pengamatan antara $500-1000 \mathrm{~m}$. Penentuan titik sampel berdasarkan keadaan lokasi penelitian yang memungkinkan untuk memasang perangkap lampu. Adapun pertimbangan untuk menentukan titik sampel adalah lokasinya sedikit lebih tinggi dan agak terbuka sehingga sinar lampu bisa menerangi sekitar lokasi penelitian. Pengambilan sampel dilakukan setiap satu kali dalam sebulan pada bulan gelap dan pada titik yang sama selama 12 bulan. Kumbang lucanid yang terbang dan yang hinggap di layar dicatat jumlah dan jenisnya.
Spesies yang belum teridentifikasi maka sampel dikumpulkan dalam suatu botol berisi alkohol $70 \%$ untuk selanjutnya diidentifikasi secara teliti di laboratorium. Identifikasi spesies kumbang lucanid mengacu kepada buku Crowson (1955), Weng \& Tung (1983), Borror et al. (1989), Mizunuma \& Nagai (1994), dan Lawrence \& Britton (1996). Apabila masih ada sampel kumbang lucanid yang belum dapat diidentifikasi berdasarkan beberapa kunci diatas maka sampel tersebut kemudian dibawa ke museum serangga LIPI Cibinong untuk diidentifikasi dan dicocokkan dengan spesimen kumbang lucanid yang terdapat di museum serangga.

\section{Analisis Data \\ Pola Keanekaragaman, Kekayaan dan Kemerataan Spesies Kumbang Lucanid}

Indeks keanekaragaman spesies $(\mathrm{H})$, kekayaan spesies (S), indeks kemerataan jenis (E) dan dominansi jenis ditentukan berdasarkan data yang diperoleh pada setiap waktu pengamatan. Penentuan tingkat keanekaragaman spesies kumbang lucanid pada tiap waktu pengamatan menggunakan indeks keanekaragaman $(\mathrm{H})$ menurut Shannon \& Weaner (Magurran, 1988), dengan rumus sebagai berikut:

Indeks keanekaragaman jenis $(\mathrm{H})$

$$
\mathrm{H}^{\prime}=-\sum \mathrm{P}_{\mathrm{i}} \text { In } \mathrm{P}_{\mathrm{i}}
$$

$P_{i}=$ proporsi tiap jenis kumbang lucanid.

Untuk menentukan tingkat

kemerataan spesies kumbang lucanid pada setiap waktu pengamatan digunakan indeks kemerataan Shannon (E) (Magurran 2004), sebagai berikut :

Indeks kemerataan spesies (E)

$$
\mathrm{E}=\mathrm{H} / \ln (\mathrm{S})
$$

$\mathrm{S}=$ jumlah spesies kumbang lucanid

Analisis statistik yang digunakan adalah program Statistica versi 6, Anova satu arah (one-way Anova) dan uji Tukey's pada taraf kepercayaan 95\% dipakai untuk mengetahui perbedaan kekayaan spesies, kelimpahan spesies, nilai keanekaragaman spesies dan nilai kemerataan spesies kumbang lucanid pada setiap waktu pengamatan. 


\section{HASIL DAN PEMBAHASAN}

Jumlah spesies yang ditemukan selama penelitian sebanyak 674 ekor yang meliputi 11 spesies. Dari 11 spesies yang ditemukan Hexarthrius buqueti, Prosopocoilu astocoides dan Cyclommatus. canaliculatus merupakan spesies yang selalu muncul selama satu tahun (12 bulan pengamatan atau 100\%). Spesies yang persentase kehadirannya menurun dengan bertambahnya kerusakan hutan adalah Prosopocoilu astocoides, Dorcus bucephalus, Odontolabis bellicosa,
Hexarthrius rhinoceros dan Dorcus taurus. Hal berbeda ditemukan pada Prosopocoilus zebra, kehadirannya sering ditemukan pada hutan tidak terganggu, kemudian menurun pada hutan kurang terganggu dan naik lagi pada hutan sangat terganggu. Dua spesies yang persentase kehadiranya menurun dengan bertambahnya kerusakan hutan bahkan tidak dijumpai pada hutan sangat terganggu adalah Allotopus rosenbergi, dan Prosopocoilu decipien, sedangkan Prosopocoilu passoloides terjadi sebaliknya (Gambar 1).

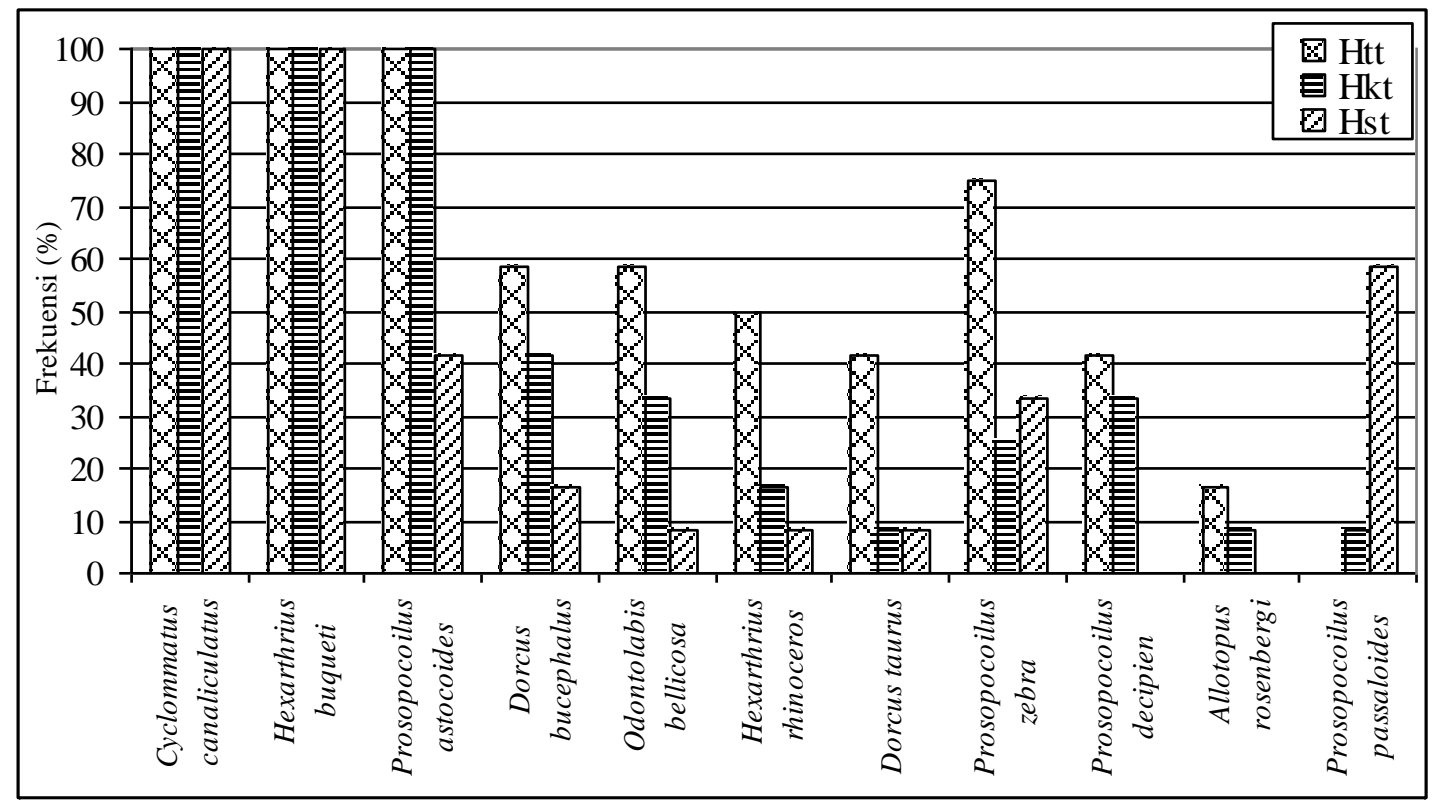

Ket: Htt: hutan tidak terganggu, Hkt: hutan kurang terganggu dan Hst: Hutan sangat terganggu

Gambar 1. Persentase kehadiran spesies kumbang lucanid hasil perangkap lampu buatan selama satu tahun pada tiga tingkat gangguan hutan

Berdasarkan bulan pengamatan terlihat bahwa pada bulan April dan Nopember paling banyak ditemukan jumlah spesiesnya yaitu sebanyak 10 spesies. Bulan berikutnya adalah Februari dan Maret yang berjumlah 9 spesies, sedangkan jumlah spesies yang paling sedikit (5 spesies) terdapat pada bulan Juli.

Kehadiran spesies kumbang lucanid setiap bulan selama setahun bervariasi antara 3 sampai 11 bulan. Dari total spesies yang ditemukan (11 spesies) terdapat tiga spesies yaitu $\quad H . \quad$ buqueti $\quad(\bar{x}=19,25 \pm 8,35$ individu/bulan), $P$. astocoides ( $\bar{x}=14,83 \pm$ 6,63 individu/bulan) dan $C$. canaliculatus $(\bar{x}=4,17 \pm 6,75$ individu/bulan) yang frekuensi kehadirannya $100 \%$ (selalu muncul setiap bulan selama setahun). Pola sebaran ketiga spesies ini hampir sama dan mengalami kenaikan jumlah individu pada bulan Maret sampai Juni (Tabel 1). 
Tabel 1. Kehadiran spesies kumbang lucanid hasil perangkap lampu buatan pada tiga tingkat gagguan hutan setiap bulan selama setahun

\begin{tabular}{lccccccccccccc}
\hline \multirow{2}{*}{ Spesies } & Des & Jan & Feb & Mar & Apr & Mei & Jun & Juli & Agt & Sep & Okt & Nov & Total \\
& 04 & 05 & 05 & 05 & 05 & 05 & 05 & 05 & 05 & 05 & 05 & 05 & bulan \\
\hline H. buqueti & + & + & + & + & + & + & + & + & + & + & + & + & 12 \\
P. astocoiedes & + & + & + & + & + & + & + & + & + & + & + & + & 12 \\
C. canaliculatus & + & + & + & + & + & + & + & + & + & + & + & + & 12 \\
D. bucephalus & + & - & + & + & + & + & + & + & + & + & + & + & 11 \\
P. zebra & + & + & + & + & + & + & + & - & - & + & + & + & 10 \\
H. rhinoceros & - & + & + & + & + & + & - & - & + & + & + & + & 9 \\
P. passaloides & - & + & + & + & + & - & - & - & + & + & + & + & 8 \\
O. bellicosa & - & - & - & + & + & - & + & - & + & + & + & + & 7 \\
D. taurus & + & + & + & - & + & + & + & - & - & - & - & - & 6 \\
P.decipien & - & - & - & - & + & + & + & + & + & - & - & + & 6 \\
A. rosenbergi & - & - & + & + & - & - & - & - & - & - & - & + & 3 \\
\hline Total spesies & 6 & 7 & 9 & 9 & 10 & 8 & 8 & 5 & 8 & 8 & 8 & 10 & 6 \\
\hline
\end{tabular}

Ket: + : spesies ditemukan; - : spesies tidak ditemukan

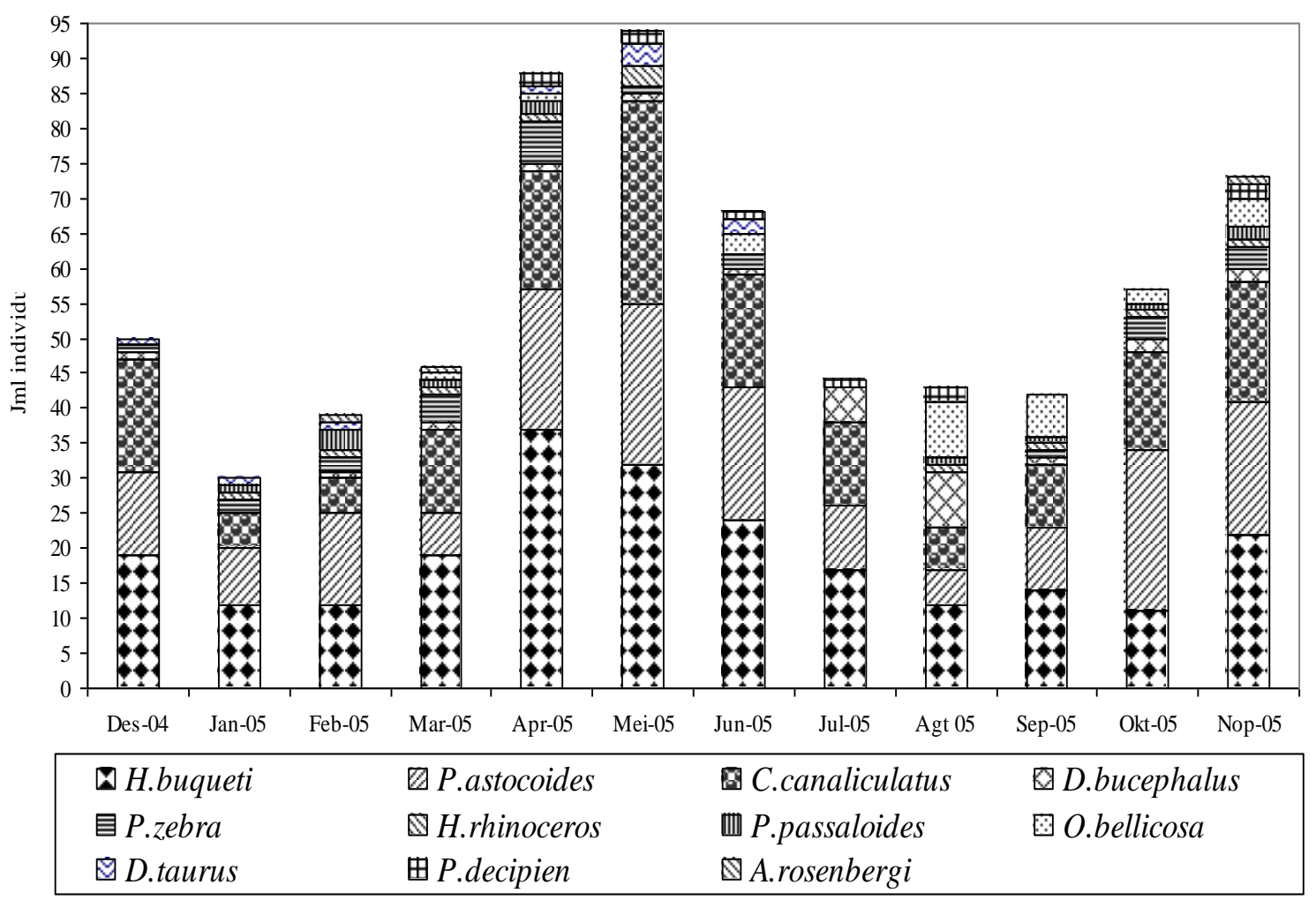

Gambar 2. Kelimpahan spesies kumbang lucanid hasil perangkap lampu buatan pada tiga tingkat gangguan hutan di Gunung Salak.

Sembilan spesies lainnya, ditemukan 8 spesies yang frekuensi kehadirannya antara $50 \%$ sampai $91,67 \%$ (muncul selama 6 sampai 11 bulan) yaitu $D$. bucephalus (11 bulan), P. zebra (10 bulan), H. rhinoceros ( 9 bulan) pengamatan atau $75 \%), \quad P$. passaloides (8 bulan atau 66,67\%), $O$. bellicosa (7 bulan), $D$. taurus dan $P$. decipien (6 bulan), namun rata-rata jumlah individunya yang muncul setiap bulan sangat rendah atau kurang dari 3 individu/bulan. Satu spesies lainnya yaitu $A$. rosenbergi hanya muncul selama 3 bulan pengamatan (Tabel 1 )

Dua dari tiga spesies kumbang lucanid yang bernilai jual tinggi seperti $D$. 
bucephalus dan $P$. decipien hampir memiliki pola sebaran yang sama, sedangkan satu spesies lainnya yaitu $A$. rosenbergi cenderung berbeda. Spesies $A$. rosenbergi hanya muncul pada bulan Februari, Maret dan Nopember, namun jumlah individunya sangat rendah ( $\bar{x}=0,25 \pm 0,45$ individu/bulan) (Tabel 1 dan Gambar 2).
Pola kelimpahan kumbang lucanid berdasarkan tipe habitat hampir menunjukkan pola yang sama. Titik terendah pertama atau jumlah individu sedikit ditemukan pada bulan Januari 2005 dan titik puncak pertama pada bulan April dan Mei 2005. Sedangkan titik terendah kedua ditemukan pada bulan Agustus 2005 dan September 2005. Titik puncak kedua terjadi pada bulan Oktober 2005 dan Nopember 2005 (Gambar 3).

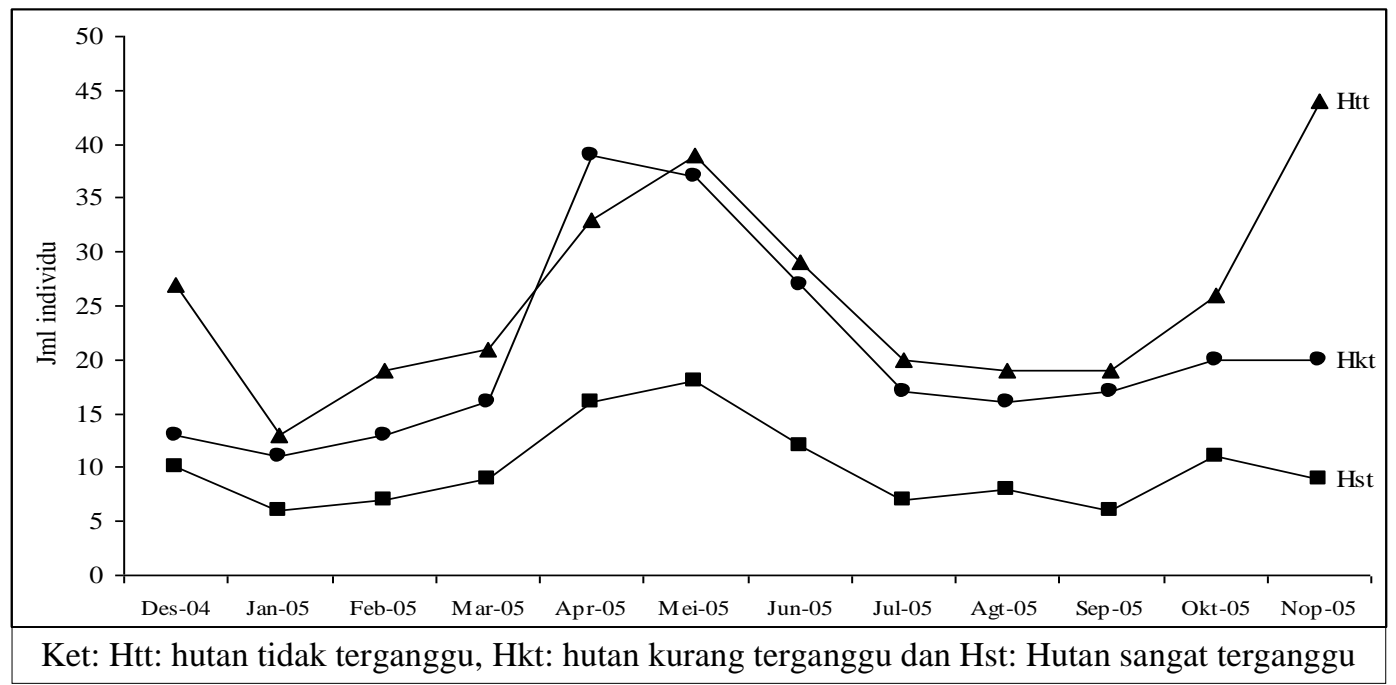

Gambar 3. Fluktuasi kelimpahan populasi kumbang lucanid hasil perangkap lampu buatan pada tiga tingkat gangguan hutan di Gunung Salak.

Berdasarkan periode pengambilan sampel tampak bahwa kelimpahan spesies dan kekayaan spesies berbeda nyata antar bulan pengamatan (Anova: $\mathrm{F}_{2 ; 204}=5,927 ; \mathrm{p}$ $<0,05 ;$ dan $\left.\mathrm{F}_{2} ; 204=2,319 ; \mathrm{p}<0,05\right)$. Sedangkan nilai keanekaragaman spesies tidak menunjukkan perbedaan yang nyata (Anova: $\mathrm{F}_{2} ; 204=1,757 ; \mathrm{p}=0,064$ atau $\mathrm{p}>$ $0,05)$ demikian juga dengan nilai kemerataan spesies (Anova: $\mathrm{F}_{2} ; 204=1,431 ; \mathrm{p}=0,161$ atau $\mathrm{p}>0,05)$.

Kelimpahan spesies tertinggi terjadi bulan Mei 2005 dan hasil uji statistik berbeda nyata dengan bulan Januari - Maret dan Juli- September 2005 ( $p<0,05)$, namun tidak berbeda nyata dengan bulan-bulan lainnya. Bulan Januari 2005 merupakan kelimpahan spesies terendah dan hasil uji statistik berbeda nyata dengan bulan April, Mei dan Nopember 2005 ( $p<0,05)$, tapi tidak berbeda nyata dengan bulan lainnya.

Kekayaan spesies kumbang lucanid tertinggi ditemukan pada bulan Mei 2005 dan terendah bulan Januari 2005. Hasil uji statistik menunjukkan bahwa kekayaan spesies kumbang lucanid bulan Mei 2005 berbeda nyata dengan bulan Janurai 2005 ( $\mathrm{p}<0,05$ ), tapi tidak berbeda nyata dengan bulan lainnya. Nilai keanekaragaman dan kemerataan spesies walaupun uji statistik tidak menunjukkan perbedaan yang nyata antara periode pengamatan, tetapi berdasarkan gambar $4.6 \mathrm{c} \& \mathrm{~d}$ nilai tertinggi kedua veriabel terjadi pada bulan Mei 2005 dan terendah bulan Januari 2005.

Fluktuasi kelimpahan kumbang lucanid di alam sangat dipengaruhi oleh jumlah curah hujan setiap bulan. Kelimpahan spesies, kekayaan spesies dan keanekaragaman spesies kumbang lucanid paling tinggi ditemukan pada bulan dengan curah hujan rendah. Data curah hujan dari Badan Meteorologi dan Geofisika Wilayah I Bogor mencatat bahwa curah hujan terendah di Gunung Salak terjadi antara bulan April sampai Agustus. Hasil penelitian menunjukkan terdapat korelasi negatif antara curah hujan dengan struktur komunitas kumbang lucanid. Hal ini berarti bahwa semakin tinggi curah hujan maka 
kelimpahan individu kumbang lucanid semakin menurun. Hasil ini berbeda dengan yang dilaporkan oleh Kahono dan Noerdjito (2001) bahwa komunitas serangga (Lepidoptera, Coleoptera, Homoptera, Hymenoptera, Orthoptera, Diptera dan Trichoptera) yang dikoleksi dengan perangkap lampu (light trap) seirama dengan fluktuasi curah hujan, jika curah hujan naik maka kelimpahan serangga juga naik.

Rendahnya jumlah kumbang lucanid pada bulan dengan curah hujan yang tinggi kemungkinan juga disebabkan karena hujan mengakibatkan kondisi hutan pada malam hari berkabut, sehingga cahaya lampu terhalang. Hal ini akan mengakibatkan kumbang lucanid yang tertarik cahaya tidak keluar. Kondisi ini berbeda jika curah hujan rendah atau tidak terjadi hujan pada malam hari, maka jangkauan sinar lampu akan lebih jauh dan kumbang lucanid yang tertarik cahaya akan datang ke sumber cahaya. Hasil penelitian Yahiro dan Yano (1997) melaporkan bahwa penangkapan kumbang yang terbang karena tertarik cahaya lampu (perangkap lampu) sangat dipengaruhi oleh curah hujan, temperatur, angin dan cahaya bulan.

Faktor lain yang dapat mempengaruhi kelimpahan populasi kumbang lucanid pada bulan April dan Mei adalah kemunculan imago baru. Imago kumbang lucanid yang sudah keluar akan mencari makan dan menemukan pasangannya untuk kawin. Penelitian Smith (2003) melaporkan bahwa kumbang lucanid dewasa baik jantan maupun betina banyak muncul antara bulan Mei sampai Agustus. Sedangkan London Wildlife Trust (1998) mencatat kumbang lucanid banyak muncul dari pertengahan Mei sampai akhir Juli.

$H$. buqueti merupakan salah satu spesies yang selalu muncul setiap bulan dan pada hutan tidak terganggu fluktuasinya relatif stabil, sedangkan pada hutan kurang terganggu dan hutan sangat terganggu kelimpahannya sangat berfluktuasi dan mencapai puncaknya pada bulan April dan Mei masing-masing pada hutan kurang reganggu dan hutan sangat terganggu. Pada hutan Unocal yang merupakan hutan relatif tidak teganggu fluktuasi $H$. buqueti juga relatif stabil.
Spesies yang berjual nilai tinggi seperti A. rosenbergi pada hutan tidak terganggu hanya muncul pada bulan Februari dan Nopember. Pada hutan kurang terganggu A. rosenbergi muncul pada bulan Maret, namun demikian pada hutan sangat terganggu spesies ini tidak ditemukan. Pada hutan konsensi Unocal A. rosenbergi kemunculannya lebih sering (6 bulan) dibandingkan dengan hutan kurang terganggu dan hutan sangat terganggu.

Pola sebaran spesies H. buqueti, $P$. astocoiedes, $C$. canaliculatus dari hasil perangkap lampu buatan berdasarkan waktu (temporal) dan lokasi (spatial) relatif hampir sama, hal ini disebabkan karena respon spesies terhadap lingkungan tidak terlalu berbeda. Data ini didukung oleh analisis CCA, yang mana keberadaan ketiga spesies ini tersebar luas pada lokasi penelitian dan tidak terlalu dipengaruhi oleh parameter lingkungan atau disebut juga spesies yang bersifat generalis.

Pola fluktuasi kumbang lucanid yang diperdagangkan berbeda dengan metode perangkap lampu buatan dan lampu Unocal. Polanya sangat tergantung kepada banyaknya permintaan kumbang lucanid dari Jepang sebagai negara tujuan ekspor serta harganya di pasaran. Apabila permintaan tinggi biasanya harga kumbang lucanid mahal, sehingga masyarakat banyak berburu kumbang lucanid. Hal ini akan mengakibatkan jumlah kumbang lucanid yang dijual semakin banyak.

\section{KESIMPULAN}

1. Fluktuasi kumbang lucanid di alam mencapai puncak pada bulan April dan Mei. Pola ini sangat dipengaruhi oleh munculnya imago dan curah hujan.

2. Cyclomatus canaliculatus, Prosopocoilus astocoides dan Hexarthrius buqueti merupakan spesies kumbang lucanid yang selalu ditemukan dengan tiga cara pengumpulan data setiap bulan selama satu tahun.

3. Pola sebaran H. buqueti, P. astocoiedes, C. canaliculatus berdasarkan waktu (temporal) dan lokasi (spatial) relatif hampir sama, hal ini disebabkan karena respon spesies terhadap lingkungan tidak terlalu berbeda. 


\section{DAFTAR PUSTAKA}

Borror D.J., C.A. Triplehorn, N.F. Johnson. 1989. An Introduction to the Study of Insects. Sounders College Publishing.

Crowson R.A. 1955. The Natural Classification of the Families of Coleopteran. Nathaniel Lloyd. London.

Hosking, G.P. 1979. Trap Comparison in the Capture of Flying Coleoptera. New Zealand Entomologist 7: 87-92.

Kahono S., W.A. Noerdjito. 2001. Fluctuation of Rainfall and Insect Community in a Tropical Forest, Gunung Halimun National Park. Biodiversitas Taman Nasional Gunung Halimun (1). Pusat penelitian Biologi LIPI.

Kahono S., M. Amir. 2003. Ekosistem dan khasanah serangga Taman Nasional Gunung Halimun: Serangga Taman Nasional Gunung Halimun Jawa Bagian Barat. JICA.

Lawrence J.F., E.B. Britton. 1996. Coleoptera (Beetles) in the Insectts of Australia. Melbourne University Press, Melbourne.
London Wildlife Trust. 2000. Stag Beetle an Advice Note for Its Conservation in London.

http://www.wildlifetrust.org.uk/Lond on. [8 Juni 2005]

Magurran A.E. 1988. Ecological Diversity and Its Measurements. London. Croom Helm Limited. London.

Magguran A.E. 2004. Measuring Biological Diversity. Malden. Blackwell Publishing.

Mizunuma T., S. Nagai. 1994. Mushi-sha's Iconographic Series of Insects I. The Lucanid Beetles of the World. Mushisha's, Tokyo.

Weng V., Y. Tung. 1983. Common Malaysian Beetles. Longman. Kuala Lumpur.

Woong C.S. 2003. The Relationship Between Local Distribution and Abudance of Buterflies and Weather Factors. Koerean J. Ecol 26 (4): 199-2002.

Yahiro K., K. Yano. 1997. Ground Beetles (Coleoptera, Carabidae) Caught by a Light Trap during Ten Years. Esakia 37: 57-69 